\title{
Long-term follow-up of patients with chronic hepatitis C with sustained virologic response to interferon
}

Authors

Sandro da Costa Ferreira, $\mathrm{MD}^{1}$

Marcos de Vasconcelos Carneiro, $\mathrm{MD}^{1}$

Fernanda Fernandes Souza, $\mathrm{MD}^{1}$

Andreza Corrêa Teixeira, MD

Marcia Guimarães

Villanova, $\mathrm{MD}, \mathrm{PhD}^{1}$

José Fernando de Castro

Figueiredo, $\mathrm{MD}, \mathrm{PhD}^{2}$

Afonso Dinis Costa Passos,

$\mathrm{MD}, \mathrm{PhD}^{3}$

Leandra Naira Zambelli

Ramalho, $\mathrm{MD}, \mathrm{PhD}^{4}$

Sergio Zucoloto, $\mathrm{MD}, \mathrm{PhD}^{4}$

Ana de Lourdes Candolo

Martinelli, MD, $\mathrm{PhD}$

${ }^{1}$ Department of Medicine, Division of Gastroenterology. ${ }^{2}$ Department of Medicine,

Division of Infectious Diseases ${ }^{*}$

${ }^{3}$ Department of Social

Medicine.*

${ }^{4}$ Department of Pathology.*

*University Hospital,

Faculdade de Medicina de

Ribeirão Preto, Universidade de São Paulo, Ribeirão Preto

SP, Brazil.

Submitted on: 09/23/2009 Approved on: 11/05/2009

Correspondence to:

Prof. Dr. Ana de Lourdes

Candolo Martinelli

Department of Medicine

Division of Gastroenterology

Faculdade de Medicina de

Ribeirão Preto, Universidade de São Paulo

Avenida Bandeirantes, 3900

Ribeirao Preto - SP - Brazil CEP: 14049-900

Phone: +55-16-36022454

Fax: +55-16-36333965

E-mail:

adlcmart@fmrp.usp.br

This research was supported by Fundação de Apoio ao Ensino Pesquisa e Assistência (FAEPA), University Hospital, Faculdade de Medicina de Ribeirão Preto, Universidade de São Paulo (HCFMRP-USP).

\begin{abstract}
Background and aim: The durability of the sustained virologic response (SVR) in patients with chronic hepatitis $\mathrm{C}$ after treatment and the ideal follow-up time for these patients remains undefined. The objective of the study was to evaluate the durability of the virologic response in patients with chronic hepatitis $\mathrm{C}$ followed up for at least 12 months after SVR at HCFMRP-USP. Methods: The study was conducted on 174 patients with chronic hepatitis $\mathrm{C}$ treated with different antiviral regimens who had achieved SVR. Qualitative serum HCV-RNA was determined by the commercial kit (COBAS AMPLICOR HCV, v2.0). Results: There was predominance of male (73\%) with a mean age of $45.6 \pm 10$ years. Liver cirrhosis was present in $16.1 \%$ of the study subjects. Mean follow-up time after SVR was 47 months (12-156 months). Twenty-two patients received monotherapy with interferon; 94 received interferon plus ribavirin, and 58 received pegylated interferon plus ribavirin. A total of 134 patients $(77.0 \%)$ received one treatment course, 29 (16.7\%) received two courses, and $11(6.3 \%)$ received three courses. The distribution of HCV genotypes was: genotype $1(40.2 \%)$, genotype $3(40.8 \%)$ and genotype $2(10.3 \%)$. Genotype was undetermined in $8.7 \%$ of cases. None of the 174 patients had recurrence of HCV infection. Two cirrhotic patients developed hepatocellular carcinoma (HCC) during follow-up. Conclusions: Among patients with SVR there was no recurrence of $\mathrm{HCV}$ infection or evidence of liver disease progression in any patient followed up for a mean of 47 months after SVR, except for patients with advanced hepatic disease before treatment, who may develop HCC despite SVR. Therefore, one can assume that SVR is associated with long term good prognosis.
\end{abstract}

Keywords: hepatitis C, interferon, HCV, follow-up, hepatocellular carcinoma.

[Braz J Infect Dis 2010;14(4):330-334]@Elsevier Editora Ltda.

\section{INTRODUCTION}

Hepatitis $\mathrm{C}$ virus (HCV) is currently recognized as the major cause of chronic liver disease worldwide. HCV infects $2.2 \%$ to $3 \%$ of the world population with a total of 130 million chronic carriers that differ in terms of potential progression to liver cirrhosis and hepatocellular carcinoma (HCC). ${ }^{1,2}$

The main objective of treatment of chronic $\mathrm{HCV}$ infection is to prevent disease progression to more severe forms and to improve patient survival and quality of life. Thus far, interferon (IFN) alpha, initially administered as monotherapy and later combined with ribavirin (RBV), is the only effective regimen for the treatment of chronic HCV infection. ${ }^{3}$ Currently, the combination of pegylated IFN and RBV is the treatment of choice for chronic HCV infection. ${ }^{4,5}$

Treatment efficacy is assessed by the sustained virologic response (SVR), which is de- fined by undetectable HCV-RNA six months after the end of therapy. ${ }^{6}$

Several controlled studies have demonstrated increasing SVR rates. SVR rates of $6 \%$ to $20 \%$ have been reported with the use of conventional IFN monotherapy, and $42 \%-82 \%$ rates have been reported with the use of pegylated IFN plus RBV. ${ }^{1,7-10}$ The results of combined pegylated IFN and RBV therapy vary according to HCV genotype, with SVR rates of $42 \%$ to $50 \%$ in patients infected with genotype 1 , and of $80 \%$ in patients infected with genotype 2 or 3.,2,6

Studies have demonstrated that SVR is associated with histological improvement, assessed by liver biopsy, and with the prevention of complications, such as the development of liver cirrhosis and HCC. ${ }^{11-14}$ Thus, SVR as result of therapy is deemed as an important factor for long-term favourable prognosis, although $4.0 \%$ to $8.7 \%$ of late recurrence was observed in two studies. ${ }^{10,15}$ 
In addition, some clinical studies have indicated the occurrence of HCC cases in cirrhotic patients who had developed SVR after antiviral treatment, emphasizing the need to maintain HCC screening regardless of treatment response. ${ }^{11,16-19}$

Despite favourable good long-term prognosis for patients with SVR, the durability of SVR and the optimal length of follow-up for these patients is still open to controversy. ${ }^{10,14,16,18-20}$

Thus, the objective of the present study was to determine the durability of SVR in chronic HCV patients treated with different forms of IFN, either in monotherapy or in combination with RBV, and followed up for at least 12 months after SVR, receiving care at the Hepatitis Outpatient Clinic of the University Hospital, Faculdade de Medicina de Ribeirão Preto, Universidade de São Paulo (HCFMRP-USP) from 1994 to 2007.

\section{MATERIAL AND METHODS}

Clinical and laboratory data and liver biopsies of 174 patients known to have developed SVR after therapy with different forms of IFN monotherapy or IFN combined with RBV were eligible for the study. Before antiviral treatment, all patients had serum positivity for HCV-RNA determined by the polymerase chain reaction (PCR) (commercial COBAS AMPLICOR HCV method, v2.0, Roche Molecular Systems, Branchburg, USA) and elevated ALT on at least one occasion (> 1.5 X Upper Limit of Normal). HCV genotype was determined in all patients by the InnoLiPA assay (INNOLIPA, Versant TM HCV Genotype Assay, LiPA, Mfd In Belgium for Bayer Corporation, Tarrytown, NY 10591-5097 USA). Patients co-infected with HIV or hepatitis B (HBV), and individuals affected by other chronic liver diseases in addition to $\mathrm{HCV}$ were excluded. A liver biopsy was available for 166 patients (95.4\%) before antiviral treatment.
Liver biopsies, performed under real time ultrasound guidance using a Trucut $14 \mathrm{G}$ needle, were reported according to the necro-inflammatory activity (HAI scores 0 to 18 ) and to the stage of liver fibrosis (scores 0 to 4 ) using the classification of Knodell et al. (1981), ${ }^{21}$ modified by Desmet et al. (1994). ${ }^{22}$ Dose and duration of administered antiviral therapy were based on international recommendations at the time of treatment indication. ${ }^{3,5,7-9}$ Interferon alpha $2 \mathrm{a}$ or alpha $2 \mathrm{~b}$ was used as standard interferon ( 3 million units 3 times a week for 24 or 48 weeks) and pegylated interferon was used at weekly doses of $180 \mu \mathrm{g} / \mathrm{kg}$ (alpha $2 \mathrm{a}$ ) or $1.5 \mu \mathrm{g} / \mathrm{kg}$ (alpha $2 \mathrm{~b}$ ) for 48 weeks.

SVR was defined as HCV-RNA negativity six months after the end of therapy, as determined by commercial kits (COBAS AMPLICOR HCV v2.0; sensitivity limit of $50 \mathrm{IU} / \mathrm{mL}$ ). Ever since SVR was established, all patients were annually tested for serum HCV-RNA. In addition, cirrhotic patients were also evaluated every six months for liver tests (bilirubin, prothrombin time, albumin and liver enzymes) and screening for HCC (liver ultrasound and serum alpha-fetoprotein).

Length of SVR was determined as the time elapsed from the date SVR had been established and the date of the latest qualitative negative HCV-RNA test. Patients with a SVR length less than 12 months were excluded from the study.

\section{RESULTS}

There was predominance of male (73\%) and caucasian (88.5\%), with a mean patient age of $45.6 \pm 10$ years. Liver cirrhosis was present in 28 (16.1\%) patients. Mean follow-up time after SVR was of 47 months (range: 12 to 156 months).

The main patient characteristics according to the used therapeutic regimen for treating HCV infection are summarized in Table 1.

Table 1. Baseline patient characteristics and pretreatment liver histology of 174 patients with chronic hepatitis $C$ according to antiviral regimens

\begin{tabular}{|c|c|c|c|}
\hline Characteristics & $\begin{array}{l}\text { Interferon } \\
(\mathrm{n}=22)\end{array}$ & $\begin{array}{c}\text { Interferon + ribavirin } \\
(\mathrm{n}=94)\end{array}$ & $\begin{array}{l}\text { Peginterferon + ribavirin } \\
\quad(n=58)\end{array}$ \\
\hline Gender $(\mathrm{M} / \mathrm{F})$ & $17 / 5$ & $69 / 25$ & $41 / 17$ \\
\hline Mean age (years) & $42.3 \pm 11.3$ & $46.2 \pm 10.3$ & $44.7 \pm 9.8$ \\
\hline \multicolumn{4}{|l|}{ Sources of HCV infection } \\
\hline Intravenous drug user $(\mathrm{n}=21)$ & $3(13.6 \%)$ & $10(10.6 \%)$ & $8(13.7 \%)$ \\
\hline Blood transfusion $(n=31)$ & $2(9.0 \%)$ & 15 (15.9\%) & $14(24.1 \%)$ \\
\hline Others $^{\dagger}(\mathrm{n}=85)$ & $14(63.6 \%)$ & $54(57.4 \%)$ & 17 (29.3\%) \\
\hline Unknown $(\mathrm{n}=66)$ & $9(40.9 \%)$ & $25(26.5 \%)$ & $32(55.1 \%)$ \\
\hline \multicolumn{4}{|l|}{ Liver biopsy ${ }^{\ddagger}$} \\
\hline $\mathrm{F} 0 / \mathrm{F} 1(\mathrm{n}=71)$ & 13 (81.2\%) & $38(40.9 \%)$ & $20(35.1 \%)$ \\
\hline $\mathrm{F} 2(\mathrm{n}=67)$ & $1(6.3 \%)$ & $35(37.6 \%)$ & $31(54.4 \%)$ \\
\hline $\mathrm{F} 3 / \mathrm{F} 4(\mathrm{n}=28)$ & 2 (12.5\%) & $20(21.5 \%)$ & $6(10.5 \%)$ \\
\hline
\end{tabular}

${ }^{\dagger}$ Occupational hazard, inhalatory illicit drug use, parenteral fortifiers, tattoo. $\mathrm{n}$ - number of patients.

${ }^{\ddagger}$ Grade of fibrosis [Knodell et al. (1981), ${ }^{21}$ modified by Desmet et al. (1994)].22 
Twenty-two patients received IFN alpha-2a or $2 \mathrm{~b}$ monotherapy, 152 received combined therapies (IFN alpha $2 \mathrm{a}$ or $2 \mathrm{~b}$ plus RBV in 94 cases and PEG-IFN alpha $2 \mathrm{a}$ or $2 \mathrm{~b}$ plus RBV in 58). A total of 104 patients (77\%) received one treatment course, $29(16.7 \%)$ received two coursess, and $11(6.3 \%)$ received three courses.

HCV genotype 1 was found in 70 patients $(40.2 \%)$, genotype 2 in 18 patients (10.3\%), and genotype 3 in $71(40.8 \%)$. In 15 patients $(8.7 \%)$ the genotype was not identified.

In 28 out of 174 patients with SVR (16.1\%), the diagnosis of liver cirrhosis was established before the beginning of treatment. In this group there was also predominance of males $(82.1 \%)$ and caucasians (92.9\%). Two patients were treated with IFN monotherapy and 26 received combined therapy (IFN in combination with RBV in 20 cases and PEG IFN in combination with RBV in 6 cases).Twenty-three patients $(82.1 \%)$ received one treatment course, 3 patients (10.7\%) received two courses, and 2 patients $(7.1 \%)$ received three courses. In this group, the infecting HCV was of genotype 1 in $28.5 \%$, genotype 2 in $10.7 \%$, and genotype 3 in $53.5 \%$; genotype was not identified in $7.3 \%$. None of the 28 cirrhotic patients presented decompensation of liver disease during a mean follow-up period of 38.5 months (range: 12 to 109 months). Screening for HCC (liver ultrasound and determination of alpha-fetoprotein every six months) was performed in all patients of this group, with HCC being detected in two patients - after 22 months of SVR in one, and after 64 months of SVR in the other. None of them had detectable serum HCV-RNA at the time of HCC diagnosis. The characteristics of these patients are shown in Table 2.

There was no recurrence of HCV infection in any of the 174 patients with SVR followed up for more than 12 months after SVR.

\section{DISCUSSION}

In the present series SVR was maintained in all cases over a mean period of observation of 47 months (range: 12 to 156 months). These data confirm results reported in other studies showing $92 \%$ to $100 \%$ rates of undetectable HCVRNA after treatment with different forms of IFN, alone or in combination with RBV, over a mean follow-up period of 1 to 12 years. ${ }^{10,13,14,16,18-20,23}$

A key question in the long-term management and follow-up of patients with SVR is the durability of the response and the extent to which it results in permanent disease remission. Late relapse rates of $0 \%$ to $9 \%$ after SVR have been reported in some studies. It should be pointed out that these studies involved different periods of follow-up, varying definitions of biochemical and virologic response, as well as PCR tests with different sensitivity thresholds for the detection of HCV-RNA. ${ }^{10,13,15,20,24}$ Such variability was of limited utility to guide clinicians about the ideal length of follow-up of treated patients with chronic hepatitis $\mathrm{C}$ who achieved SVR after antiviral treatment.

Desmond et al. ${ }^{10}$ evaluated the durability of SVR in 147 patients receiving different treatment regimens (IFN monotherapy in 34, IFN plus RBV in 76, and Peg IFN plus RBV in 37 ) and followed up for a mean period of 2.3 years (range: 0.3 to 10.3 years). During this period, $146 / 147$ patients (>99\%) showed no virologic recurrence. Swain et al. ${ }^{25}$ evaluated the durability of SVR after treatment with pegylated IFN alpha 2a, either combined or not with RBV, in 845 patients from different studies. Only seven patients (1\%) showed detectable serum HCV-RNA after a mean time of 391 to 1076 days of follow-up. These data emphasize that a relapse after obtaining SVR in patients with chronic hepatitis C treated with different forms of IFN is a rare occurrence.

Some studies have shown that serum HCV-RNA negativity results in similar changes in intrahepatic HCV-RNA. ${ }^{26}$

Table 2. Patient characteristics and laboratory features of the two patients with cirrhosis and SVR who developed HCC during follow-up

\begin{tabular}{lcc}
\hline Characteristics & Case $\mathbf{1}$ & Case $\mathbf{2}$ \\
\hline Age (years) & 64 & 53 \\
\hline Gender & Female & Male \\
\hline HCV Genotype & Unidentified & 3 \\
\hline Previous liver cirrhosis & Yes & Yes \\
\hline Time after SVR (months) & 64 & 22 \\
\hline Alpha fetoprotein $(\mathrm{ng} / \mathrm{mL})$ & 242 & 4.20 \\
\hline${\text { Lesion size }(\mathrm{cm})^{\ddagger}}^{\dagger}$ & 5.5 & 2.0 \\
\hline
\end{tabular}

${ }^{\dagger}$ Time after SVR when HCC was first detected.

*Evaluated by liver ultrasound. 
However, it is still being questioned whether negativity of serum HCV-RNA induced by antiviral treatment results in complete elimination of HCV or whether the virus persists in small amounts in the hepatocytes. In studies in which less sensitive assays (sensitivity of 1000 copies $/ \mathrm{mL}$ ) were used for the detection of HCV RNA in serum, approximately $95 \%$ of the patients with SVR did not present detectable hepatic HCV-RNA during a follow-up period of 1 to 2 years after the end of treatment. ${ }^{13,26-28}$ However, despite serum HCV-RNA negativity, patients may occasionally present low levels of detectable virus in the liver tissue. This condition has been demonstrated to be a predictor of high probability of later recurrence of $\mathrm{HCV}$ infection. ${ }^{26}$

SVR following antiviral treatment can translate into improvement of liver histology, thus preventing progression to more severe forms of disease ${ }^{12,13,16}$ and to development of HCC. ${ }^{11}$ However, even though SVR prevents progression of liver disease to cirrhosis, there is a risk of developing HCC in patients who already have cirrhosis at the time of treatment initiation. ${ }^{16-19,29,30}$ The effects of HCV-RNA, even at low levels, on carcinogenesis have not been fully clarified and more detailed studies are needed.

In the present study, 28 patients had a diagnosis of cirrhosis prior to treatment, with two of them developing HCC 22 and 64 months after SVR. Neither patient had detectable HCV-RNA in serum at the time of HCC diagnosis. Bruno et al. ${ }^{19}$ reported one case of HCC involving one cirrhotic patient in a series of 32 patients after SVR. Chavalitdhamrong et al. ${ }^{18}$ in a study involving long-term follow-up of $171 \mathrm{pa}-$ tients with SVR - 27 of whom were cirrhotics before treatment -, detected the development of HCC in 3 patients 14, 18 and 29 months after discontinuation of antiviral treatment. Two of them had a diagnosis of cirrhosis before the beginning of treatment.

Because of the risk, even though low, of the development of HCC in patients with cirrhosis due to HCV and with SVR, a regular follow-up of these patients is recommended with periodic abdominal ultrasound examination at six months intervals..$^{17-19,30}$ The present data support this recommendation.

Except for the two cases of HCC, none of the patients with SVR in the present series presented any evidence of progression of liver disease assessed clinically and biochemically by routine tests (serum aminotransferases and liver function tests). Since there were no liver biopsies available during follow-up, our data do not contribute to the evaluation of a possible histological improvement following SVR or of the possible persistence of intrahepatic HCV-RNA.

In conclusion, there was no recurrence of HCV infection in any of the 174 patients submitted to antiviral therapy who obtained SVR after a mean follow-up of 47 months (range: 12 to156 months). In addition, there was no clinical or laboratory evidence of liver disease progression after SVR, emphasizing the favourable long-term prognosis for patients who develop SVR. It should be pointed out that that disease decompensation did not occur in any of the patients with liver cirrhosis, although two of them developed HCC. This underscores the importance of early treatment of infection before severe liver damage sets in with the risk of progression to HCC, and the importance of continued HCC screening for patients who already have cirrhosis.

\section{ACKNOWLEDGEMENTS}

Research supported by Fundação de Apoio ao Ensino Pesquisa e Assistência (FAEPA), University Hospital, Faculdade de Medicina de Ribeirão Preto, Universidade de São Paulo (HCFMRP-USP). We wish to thank the staff of the Hepatitis Outpatient Clinic and of the group of Clinical and Surgical Hepatology of HCFMRP-USP.

\section{REFERENCES}

1. Alter MJ. Epidemiology of hepatitis C virus infection. World J Gastroenterol 2007; 13:2436-41.

2. Global Burden Of Hepatitis C Working Group. Global burden of disease (GBD) for hepatitis C. J Clin Pharmacol 2004; 44:20-9.

3. Hoofnagle JH, Lau D. Chronic viral hepatitis - benefits of current therapies. N Engl J Med 1996; 334:1470-1.

4. Fried MW, Shiffman ML, Reddy KR et al. Peginterferon alpha2a plus ribavirin for chronic hepatitis $\mathrm{C}$ virus infection. $\mathrm{N}$ Engl J Med 2002; 347:975-82.

5. Hadziyannis SJ, Sette Jr H, Morgan TR et al. Peginterferonalpha2a and ribavirin combination therapy in chronic hepatitis C: a randomized study of treatment duration and ribavirin dose. Ann Intern Med 2004; 140:346-55.

6. Strader DB, Wright T, Thomas DL, Seeff LB. Diagnosis, management, and treatment of hepatitis C. Hepatology 2004; 39:1147-71.

7. McHutchison JG, Gordon SC, Schiff ER et al. Interferon alpha-2b alone or in combination with ribavirin as initial treatment for chronic hepatitis C. Hepatitis Interventional Therapy Group. N Engl J Med 1998; 339:1485-92.

8. Poynard T, Marcellin P, Lee SS et al. Randomised trial of interferon alpha2b plus ribavirin for 48 weeks or for 24 weeks versus interferon alpha2b plus placebo for 48 weeks for treatment of chronic infection with hepatitis $\mathrm{C}$ virus. International Hepatitis Interventional Therapy Group. Lancet 1998; 352:1426-32.

9. Manns MP, McHutchison JG, Gordon SC et al. Peginterferon alpha-2b plus ribavirin compared with interferon alpha- $2 b$ plus ribavirin for the initial treatment of chronic hepatitis $\mathrm{C}$ : a randomised trial. Lancet 2001; 358:958-65.

10. Desmond CP, Roberts SK, Dudley F et al. Sustained virological response rates and durability of the response to interferonbased therapies in hepatitis $C$ patients treated in the clinical setting. J Viral Hepat 2006; 13:311-5.

11. Yoshida H, Tateishi R, Arakawa Y et al. Benefit of interferon therapy in hepatocelular carcinoma prevention for individual patients with chronic hepatitis C. Gut 2004; 53:425-30.

12. Shiratori $Y$, Imazeki F, Moriyama $\mathrm{M}$ et al. Histologic improvement of fibrosis in patients with hepatitis $C$ who have sustained response to interferon therapy. Ann Intern Med 2000; 132:517-24. 
13. Marcellin P, Boyer N, Gervais A et al. Long-term histologic improvement and loss of detectable intrahepatic HCV RNA in patients with chronic hepatitis $\mathrm{C}$ and sustained response to interferon-alpha therapy. Ann Intern Med 1997; 127:875-81.

14. Formann E, Steindl-Munda P, Hofer $\mathrm{H}$ et al. Long-term follow-up of chronic hepatitis $\mathrm{C}$ patients with sustained virological response to various forms of interferon-based anti-viral therapy. Aliment Pharmacol Ther 2006; 23:507-11.

15. Khokhar N. Late relapse in chronic hepatitis $\mathrm{C}$ after sustained viral response to interferon and ribavirin. J Gastroenterol Hepatol 2004; 19:471-2.

16. Veldt BJ, Saracco G, Boyer N et al. Long term clinical outcome of chronic hepatitis $\mathrm{C}$ patients with sustained virological response to interferon monotherapy. Gut 2004; 53:1504-8.

17. Yamaura T, Matsumoto A, Rokuhara A et al. Development of small hepatocellular carcinoma in a patient with chronic hepatitis $\mathrm{C}$ after 77 months of a sustained and complete response to interferon therapy. J Gastroenterol Hepatol 2002; 17:1229-35.

18. Chavalitdhamrong $\mathrm{D}$, Tanwandee T. Long-term outcomes of chronic hepatitis $\mathrm{C}$ patients with sustained virological response at 6 months after the end of treatment. World J Gastroenterol 2006; 12:5532-5.

19. Bruno S, Battezzati PM, Bellati G et al. Long-term beneficial effects in sustained responders to interferon-alpha therapy for chronic hepatitis C. J Hepatol 2001; 34:748-55.

20. Lau DT, Kleiner DE, Ghany MG et al. 10-Year follow-up after interferon-alpha therapy for chronic hepatitis C. Hepatology 1998; 28:1121-7.

21. Knodell RG, Ishak KG, Black WC et al. Formulation and application of a numerical scoring system for assessing histological activity in asymptomatic chronic active hepatitis. Hepatology 1981; 1:431-5.

22. Desmet VJ, Gerber M, Hoofnagle JH, Manns M, Scheuer PJ. Classification of chronic hepatitis: diagnosis, grading and staging. Hepatology 1994; 19:1513-20.
23. Schvarcz R, Glaumann H, Reichard O, Weiland O. Histological and virological long-term outcome in patients treated with interferon-alpha2b and ribavirin for chronic hepatitis C. J. Viral Hepat 1999; 6:237-42.

24. Reichard O, Glaumann H, Fryden A et al. Two year biochemical, virological and histological follow-up in patients with chronic hepatitis $\mathrm{C}$ responding in a sustained fashion to interferon alpha-2b treatment. Hepatology 1995; 21:918-22.

25. Swain M, Lai MY, Shiffman ML et al. Durability of sustained virological response (SVR) after treatment with peginterferon alpha $2 \mathrm{a}(40 \mathrm{kD})$ (PEGASYS) alone or in combination with ribavirin (Copegus): results of an ongoing longterm follow-up study. Hepatology 22004; 40(Suppl 1):400A; AASLD 2004. [Abstract].

26. Larghi A, Tagger A, Crosignani A et al. Clinical significance of hepatic HCV RNA in patients with chronic hepatitis $\mathrm{C}$ demonstrating long-term sustained response to interferon-alpha therapy. J Med Virol 1998; 55:7-11.

27. McHutchison JG, Poynard T, Esteban-Mur R et al. Hepatic HCV RNA before and after treatment with interferon alone or combined with ribavirin. Hepatology 2002; 35:688-93.

28. Tsuda N, Yuki N, Mochizuki K et al. Long-term clinical and virological outcomes of chronic hepatitis $\mathrm{C}$ after successful interferon therapy. J Med Virol 2004; 74:406-13.

29. Kobayashi S, Takeda T, Enomoto M et al. Development of hepatocelular carcinoma in patients with chronic hepatitis $\mathrm{C}$ who has a virological response to interferon therapy: a multicenter, retrospective cohort study of 1124 patients. Liver Int 2007; 27:186-91.

30. Ikeda M, Fujiyama S, Tanaka M et al. Risk factors for development of hepatocellular carcinoma in patients with chronic hepatitis $\mathrm{C}$ after sustained response to interferon. J Gastroenterol 2005; 40:148-56. 